\title{
Evaluating lubiprostone for effective bowel preparation before colonoscopy
}

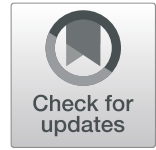

\author{
Yasser Hamada ${ }^{*^{*}}$ (D), Ibrahim Emam², Rabab Maher² and Hassan El-Garem
}

\begin{abstract}
Background: Colon preparation is a fundamental step for performing a successful colonoscopy. We aimed to evaluate the effectiveness of administering lubiprostone (LB) added to a single dose of oral polyethylene glycol (PEG) solution in achieving satisfactory colon cleanliness and decreasing the side effects.

Results: One-hundred percent of the control group patients reported that the experienced taste was worse than expected, while in the intervention group half of the patients (50\%) said that the taste was natural and $48 \%$ experienced taste worse than expected $(p<0.0001)$. Regarding Boston bowel preparation scale (BBPS), there was a significant difference in the overall Boston scale $(p=0.02)$ with more efficacy in the intervention group as $66 \%$ of patients in the intervention group had good bowel preparation (5-7) and 24\% excellent preparation (8-9). On the other hand, the overall Boston scale in the control group showed that $54 \%$ of patients were between 5 and 7 , and only $16 \%$ of patients had overall Boston scale $8-9$. In terms of the side effects of the preparation in both arms, the majority of cases in the intervention arm did not complain of any side effects (78\%), while the majority of the complaints were vomiting in $16 \%$ of the intervention cases.
\end{abstract}

Conclusion: The current evidence suggested that adding LB to the colon preparation significantly improved the tolerability and efficacy.

Keywords: Colonoscopy, Lubiprostone, Polyethylene glycol, Bowel preparation, Comparative study

\section{Background}

Colon preparation before the colonoscopy is of crucial importance and is a major factor in the success of the procedure as it helps to ensure ideal polyp detection rates [1]. In the case of poor preparation, medical costs, missed lesions, and procedure times are increased, leading to decreased patient's satisfaction [2]. Before the colonoscopy, dietary restrictions and bowel lavage using a preparation of sodium picosulfate plus magnesium oxide or polyethylene glycol (PEG) are very critical. Osmotically balanced PEG was introduced in 1980, and nowadays, it is the most commonly used bowel preparations [3].

Many patients reported some complaints as the bad taste and the large volumes required $[4,5]$. Moreover, in some cases, nausea, cramping, and vomiting were

\footnotetext{
*Correspondence: Yass.tabakh@cu.edu.eg

'Endemic Medicine Department, Faculty of Medicine, Cairo University, Cairo, Egypt

Full list of author information is available at the end of the article
}

reported. All of these side effects directly influence the adherence of the patients [6]. It was reported that the compliance rates for colonoscopy screening were only $34 \%$ [7]. In order to decrease the side effects of PEG preparation and improve its efficacy, many investigators proposed the administration of lubiprostone (LB) prior to the usage of PEG solution $[8,9]$.

LB is an approved medication for chronic idiopathic constipation that activates the chloride type 2 channels of the apical epithelial membrane in a selective manner to enhance chloride efflux in the intestinal lumen, thus maintaining its absorptive capacity [10]. The resulting fluid softens stool and increases intestinal transit [11]. Most patients rapidly metabolize and tolerate LB very well, as it acts locally inside the intestinal tract, and has very low systemic bioavailability [12]. In this study, we aimed to evaluate the effectiveness of administering LB in addition to a single dose of oral PEG solution in 
achieving satisfactory colon cleanliness and decreasing the side effects.

\section{Methods Study design}

A parallel group randomized control study was conducted throughout a period of 6 months (May-November 2019), recruiting a total of 100 patients who were referred to the gastrointestinal endoscopy and liver unit Kasr El Aini (GIELUKA) for colonoscopic examination. By means of block randomization, patients were assigned into either of the two study groups. The first group (control group, $n=50$ ) received the standard bowel preparation, two doses of PEG (120 mg of polyethylene glycol 3350 powder plus ascorbic acid), each dose added to $1 \mathrm{~L}$ of water [13], while the second group (intervention group, $n=50)$ recieved lubiprostone-based preparation, lubiprostone (LB) $(24 \mu \mathrm{g})$ tablets twice daily for 2 days, then only a single dose PEG $12 \mathrm{~h}$ before the colonoscopy. Both groups received only clear fluids for $24 \mathrm{~h}$ prior to colonoscopy. A written informed consent was obtained from all patients included.

\section{Inclusion and exclusion criteria}

Adult patients (18-65 years) of both genders, with average bodyweight, were included. Patients with chronic diarrhea, known or suspected ileus, gastrointestinal obstruction, gastric retention (gastro-paresis), rectal impaction, toxic colitis, toxic megacolon, uncontrolled inflammatory bowel disease presenting in severe activity, or bowel perforation were excluded. Moreover, we excluded pregnant or breastfeeding females, patients with previous significant gastrointestinal surgery, patients with uncontrolled pre-existing electrolyte abnormalities, patients with a severe renal impairment, and patients who require emergency colonoscopy without bowel preparation.

\section{Data collection}

Demographic data were obtained from all included patients, followed by complete colonoscopic examination with intravenous propofol sedation. The degree of bowel preparation was evaluated according to Boston bowel preparation scale (BBPS). Moreover, patients' feedback regarding tolerability and accessibility was also assessed using the 5-point Treatment Acceptability Questionnaire.

\section{BBPS}

The main objective of this scale was to evaluate specific issues that are influencing bowel preparation quality, as described by Kastenberg et al. [1]. According to the quality of the preparation, each colonic segment is graded from 0 to 3 . By adding the score for all three segments, the overall score is obtained, resulting in a score between 0 and 9. A score below 4 is considered a bad preparation, resulting in a repeat procedure recommendation. The score of 5-7 is considered to be good preparation, whereas the score of $8-9$ is considered to be excellent.

\section{Statistical analysis}

With a sample size of at least 78 (39/group), we had a power of $90 \%$ to assess whether the mean Boston scale was significantly higher in the lubiprostone group $(\sim 7.25$ (1)) compared to its mean value in the control group of $\sim 6.5$ (1), using a two-sample means test and a significance level of 0.05 . Descriptive analysis was performed using STATA 15 and was described as mean and standard deviation (SD). Categorical variables were defined as frequency and percentage. The difference between the two groups was made using the chi-square test for categorial variables and the Student $t$-test for quantitative variables. $p$-values of less than 0.05 were considered to be significant.

\section{Ethics and consent to participate}

Being conformed to the ethical guidelines of the 1975 Declaration of Helsinki and its later amendments revised in Seoul, Korea, October 2008 as reflected in previous approval by the institution's human research committee, the study protocol was approved by the research ethical committee of the endemic medicine department and the institutional review board of the faculty of medicine, Cairo University. All patients had signed a written informed consent before the start of any procedure related to the study. The personal data were concealed and replaced by numbers for patient's confidentiality.

\section{Results}

Table 1 shows the demographic data of the included patients. In the intervention group, $42(84 \%)$ of included patients were aged $18-30$, compared to $14(28 \%)$ in the control group $(p<0.0001)$. Both genders were

Table 1 Demographic characteristics of the included patients

\begin{tabular}{llll}
\hline & Control $(\boldsymbol{n}=\mathbf{5 0})$ & Intervention $(\boldsymbol{n}=\mathbf{5 0 )}$ & $\boldsymbol{p}$-value \\
\hline Age & & & \\
$18-30$ & $14(28 \%)$ & $42(84 \%)$ & $<0.0001$ \\
$30-40$ & $11(22 \%)$ & $6(12 \%)$ & \\
$40-50$ & $14(28 \%)$ & $2(4 \%)$ & \\
$50-60$ & $8(16 \%)$ & 0 & \\
$>60$ & $3(6 \%)$ & 0 & 0.40 \\
Gender & & & 0.02 \\
$\quad$ Male/female & $36 / 14$ & $32 / 18$ & \\
First colonoscopy & $32(64 \%)$ & $41(82 \%)$ & \\
\hline
\end{tabular}


represented in both groups $(p=0.40)$. This was the first colonoscopy experience for the majority of the included patients $(82 \%$ of the intervention and $64 \%$ of the control groups). Regarding comorbidities, $72 \%$ of the patients did not report any comorbidities; however, $18 \%$ of patients were hypertensive, and only $4 \%$ were diabetic.

The main concerns before colonoscopy in the intervention group were purgatives ( $72 \%$ vs. $20 \%, p<0.0001$ ), sedation ( $38 \%$ vs. $70 \%, p=0.001)$, and colonoscopy $(80 \%$ vs. $66 \%, p=0.10)$, compared to the control group. Interestingly, $100 \%$ of the control group reported that the experienced taste was worse than expected, while in the intervention group, half of the patients (50\%) said that the taste was natural and $48 \%$ experienced a taste worse than expected $(p<0.0001)$. When the patients were asked about the amount of liquid they can consume, their answers were comparable in both groups $(p=0.70)$. The large liquid volume and bad taste are the main parameters that discouraged patients in the control group. In the intervention group, the patients reported bad taste and diarrhea as the main parameters that discouraged them. When we asked the patients about how easy it was to consume the study preparation, we found a significant difference between both groups $(p<0.0001) ; 80 \%$ of the control group reported difficult or very difficult, while only $12 \%$ in the intervention group chose difficult and $66 \%$ tolerable. Therefore, all patients $(100 \%)$ in the control group would have used a different purgative if they had the choice, compared to $26 \%$ in the intervention group $(p<0.0001)$, (Table 2$)$.

Regarding the side effects of the preparation in both arms, the majority of cases in the intervention group did not complain of any side effects (78\%), while the majority of the complaints were vomiting in $16 \%$ of the cases. Only $22 \%$ reported no side effects from the preparation in the control group, but 34\% complained of abdominal pain and vomiting (Table 3 ).

With respect to BBPS, there was a significant difference in the overall Boston scale (0.02) with more efficacy in the intervention group as $66 \%$ of patients had good bowel preparation (5-7) and $24 \%$ excellent preparation (8-9). On the other hand, the overall Boston scale in the

Table 2 Patient satisfaction

\begin{tabular}{|c|c|c|c|c|}
\hline \multicolumn{2}{|l|}{ Parameters } & \multirow{2}{*}{$\begin{array}{l}\text { Control }(n=50) \\
10\end{array}$} & \multirow{2}{*}{$\begin{array}{l}\text { Intervention }(\boldsymbol{n}=\mathbf{5 0}) \\
36\end{array}$} & \multirow{2}{*}{$\frac{p \text {-value }}{<0.0001}$} \\
\hline What concerns you most before colonoscopy & Purgative & & & \\
\hline & Sedation & 35 & 19 & 0.001 \\
\hline & Colonoscopy & 33 & 40 & 0.1 \\
\hline \multirow[t]{3}{*}{ I experienced the taste as } & Neutral & 0 & 25 & $<0.0001$ \\
\hline & Worse than expected & 50 & 24 & \\
\hline & Better than expected & 0 & 1 & \\
\hline \multirow[t]{5}{*}{ Maximum volume of liquid you would be able to consume } & $0.5 \mathrm{~L}$ & 9 & 6 & 0.7 \\
\hline & $1 \mathrm{~L}$ & 27 & 27 & \\
\hline & $2 \mathrm{~L}$ & 14 & 16 & \\
\hline & $3 L$ & 0 & 1 & \\
\hline & Maximum volume (L) median (IQR) & $1(1-2)$ & $1(1-2)$ & 0.3 \\
\hline \multirow[t]{4}{*}{ What would discourage you most } & Bad taste & 47 & 48 & 0.6 \\
\hline & Bad smell & 0 & 2 & 0.1 \\
\hline & Too large liquid volume & 31 & 8 & $<0.0001$ \\
\hline & Diarrhea & 7 & 19 & 0.006 \\
\hline \multirow[t]{4}{*}{ How easy or difficult was it to consume the study drugs } & Very difficult & 11 & 0 & $<0.0001$ \\
\hline & Difficult & 29 & 6 & \\
\hline & Tolerable & 9 & 33 & \\
\hline & Easy & 1 & 11 & \\
\hline \multirow[t]{2}{*}{ If I had the choice, I would for next colonoscopy } & Use a different purgative & 50 & 13 & $<0.0001$ \\
\hline & Use this purgative & 0 & 36 & \\
\hline \multirow[t]{4}{*}{ The overall experience of the preparation } & Poor & 26 & 12 & $<0.0001$ \\
\hline & $\mathrm{Bad}$ & 12 & 0 & \\
\hline & Fair & 11 & 15 & \\
\hline & Good & 1 & 23 & \\
\hline
\end{tabular}


Table 3 Side effects

\begin{tabular}{lll}
\hline & Control $(\boldsymbol{n = 5 0 )}$ & Intervention $(\boldsymbol{n}=\mathbf{5 0})$ \\
\hline $\begin{array}{l}\text { Experiencing side effects } \\
\text { Side effects }\end{array}$ & $39(78 \%)$ & $11(22 \%)$ \\
No & $11(22 \%)$ & $39(78 \%)$ \\
Abdominal pain & $11(22 \%)$ & $1(2 \%)$ \\
Vomiting & $9(18 \%)$ & $8(16 \%)$ \\
Abdominal pain and vomiting & $17(34 \%)$ & $1(2 \%)$ \\
Abdominal pain and headache & $1(2 \%)$ & 0 \\
Abdominal pain, vomiting and headache & 0 & $1(2 \%)$ \\
\hline
\end{tabular}

control group showed that $54 \%$ of patients were between 5 and 7 , and only $16 \%$ of patients had overall Boston scale 8-9 (Table 4).

\section{Discussion}

Diagnostic accuracy and therapeutic safety in colonoscopy are significantly impacted by the quality of bowel preparation [14-17]. In this prospective comparative study, we addressed the quality of PEG preparation and patient satisfaction in both groups. Our findings demonstrated that adding LB to the preparation significantly improved the tolerability of the preparation. Additionally, it was associated with a lower incidence of adverse events, except for some cases of vomiting. In terms of efficacy, and according to the BBPS, the overall good and excellent outcomes of the intervention group were much higher than the standard group $(p=0.02)$. These findings indicate that the addition of LB produced a better colon cleansing, especially in the right colon. In addition, the

Table 4 BBPS

\begin{tabular}{|c|c|c|c|}
\hline & Control $(n=50)$ & Intervention $(n=50)$ & $p$ \\
\hline \multicolumn{4}{|c|}{ Ascending colon score } \\
\hline 1 & 25 & 16 & 0.1 \\
\hline 2 & 24 & 32 & \\
\hline 3 & 1 & 2 & \\
\hline \multicolumn{4}{|c|}{ Transverse colon score } \\
\hline 1 & 15 & 6 & 0.02 \\
\hline 2 & 29 & 29 & \\
\hline 3 & 6 & 15 & \\
\hline \multicolumn{4}{|c|}{ Descending colon score } \\
\hline 1 & 8 & 0 & $<0.0001$ \\
\hline 2 & 30 & 24 & \\
\hline 3 & 12 & 26 & \\
\hline \multicolumn{4}{|c|}{ Overall Boston scale } \\
\hline$<4$ & 15 & 4 & 0.02 \\
\hline $5-7$ & 27 & 33 & \\
\hline $8-9$ & 8 & 12 & \\
\hline
\end{tabular}

reduced need to repeat procedures in the LB group showed the significant impact of LB in the bowel preparation regimens.

Previous studies reported a success rate of PEG-based preparations of 56 to $76 \%$ for bowel cleansing. In our study, bowel preparation with the addition of LB has been effective in up to $90 \%$ of participants [18]. The rapid and enhanced colonic passage time with LB, together with the enhanced duration of bowel movement, may have contributed to the efficacy [19]. At present, the greatest obstacle for patient tolerance and adherence is the large volume of PEG-based preparation and the associated distension, fever, nausea, and vomiting. Small volume PEG preparations provide an effective alternative to regular volume preparations to decrease bowel preparation pain and inconvenience [8].

Banerjee and colleagues evaluated the adequacy and efficacy of LB and PEG as a colonoscopy preparation. They found that excellent preparation was observed in $66.5 \%$ in the LB group and $38 \%$ in the standard group $(p<0.01)$, according to the BBPS scale [8]. Stengel and Jones assessed the tolerability, safety, and efficacy of LB prior to a single dose of PEG preparation without dietary restriction. They found that the addition of LB enhanced the colon cleansing in the whole colon. They showed that the total procedure time and abdominal bloating were significantly decreased in the LB group compared to the second group. However, they could not find any significant reduction in nausea in both groups [9].

Split dosing to improve patient tolerance has been recommended [20, 21]. However, Ell et al. have demonstrated in the meta-analysis that more than $70 \%$ of the patients had only a single intake of dosing [22]. Therefore, the timing of the intake can be decided based on the convenience of the patient. Our findings appear similar. Furthermore, our study is noteworthy because we included all patients referred for colonoscopy and not only colorectal cancer screens. There have been no dietary restrictions.

This is the first study in Egypt to show that even lower doses of PEG will contribute to sufficient bowel cleaning 
by incorporating LB. The usage of a more practical single-day PEG regimen will certainly boost patient adherence in future with the CRC screening guidelines. In fact, a preparation for a better colonoscopy was recently recommended on that same day.

The present study has some limitations, as it is a single-center study where only outpatients were recruited. Compliance and the outcomes could be enhanced by fairly mobile patients with a clear clarification of the planning procedures prior to the treatment. Moreover, the lesion abnormality rate was not assessed. It was not possible for us to speculate on the relationship between enhanced bowel preparation and an improved adenoma detection rate. In earlier studies, however, improved BBPS scores were associated with increased polyp detection rate.

The incidence and mortality of colorectal cancer decreased by diagnostic colonoscopies with exclusion samples of adenomatous polyps. However, patient compliance and tolerability have been significantly impacted by the obstacles of a large volume bowel preparation and the pre-procedure dietary restrictions. Our study demonstrated that LB pre-treatment 2 days before colonoscopy would enhance bowel cleansing with a substantially reduced rate of repeat procedures. Even lower doses of PEG could be used without any effect on the overall preparation quality.

\section{Conclusion}

The current study shows a strong evidence that using lubiprostone is effective for sufficient bowel cleansing prior to colonoscopy, in comparison to the standard of care PEG preparation. Lubiprostone usage allowed reducing the volume of PEG solution needed during colon preparation which resulted in better patient satisfaction and tolerability of the preparation, while maintaining equivalent colon cleanliness results. Applying the same preparation strategy to a larger number of patients would allow better evaluation of the adenoma detection rate.

\section{Abbreviations}

PEG: Polyethylene glycol; LB: Lubiprostone; GIELUKA: Gastrointestinal endoscopy and liver unit Kasr El Aini; BBPS: Boston bowel preparation scale; SD: Standard deviation; BMI: Body mass index

\section{Acknowledgements}

For the patients and the authors for completing the study and manuscript

\section{Authors' contributions}

All listed authors have read and approved the manuscript. Y H: planning the study, colonoscopy of the studied patients, manuscript writing and editing. I E: patient recruitment and data analysis. $\mathrm{R} \mathrm{M}$ : preparation of the manuscript and statistical analysis. H EG: revising and finalizing the manuscript

\section{Funding}

No funds or grants were received for completion of this work.
Availability of data and materials

Available upon reasonable request

\section{Declarations}

Ethics approval and consent to participate

Being conformed to the ethical guidelines, the study protocol was approved by the research ethical committee of the endemic medicine department and the institutional review board of the faculty of medicine, Cairo University. All patients had signed a written informed consent before the start of any procedure related to the study. The personal data were concealed and replaced by numbers for patient's confidentiality.

\section{Consent for publication \\ Not applicable}

\section{Competing interests}

The authors declare that they have no competing interest.

\section{Author details}

${ }^{1}$ Endemic Medicine Department, Faculty of Medicine, Cairo University, Cairo, Egypt. ${ }^{2}$ Student Hospital, Cairo University Hospitals, Cairo, Egypt.

Received: 23 November 2020 Accepted: 4 March 2021

Published online: 20 March 2021

\section{References}

1. Kastenberg D, Bertiger G, Brogadir S (2018) Bowel preparation quality scales for colonoscopy. World J Gastroenterol 24(26):2833-2843. https://doi.org/1 0.3748/wjg.v24.i26.2833

2. Rex DK, Schoenfeld PS, Cohen J, Pike IM, Adler DG, Fennerty MB, Lieb JG II, Park WG, Rizk MK, Sawhney MS, Shaheen NJ, Wani S, Weinberg DS (2015) Quality indicators for colonoscopy. Gastrointest Endosc 81(1):31-53. https:// doi.org/10.1016/j.gie.2014.07.058

3. Franco DL, Leighton JA, Gurudu SR (2017) Approach to incomplete colonoscopy: new techniques and technologies. Gastroenterol Hepatol (N Y) 13(8):476-483

4. Lee KJ, Park HJ, Kim HS, Baik KH, Kim YS, Park SC, Seo HI (2015) Electrolyte changes after bowel preparation for colonoscopy: a randomized controlled multicenter trial. World J Gastroenterol 21(10):3041-3048. https://doi.org/1 0.3748/wjg.v21.i10.3041

5. Adamcewicz M, Bearelly D, Porat G, Friedenberg FK (2011) Mechanism of action and toxicities of purgatives used for colonoscopy preparation. Expert Opin Drug Metab Toxicol 7(1):89-101. https://doi.org/10.1517/17425255.2 011.542411

6. Kang SH, Jeen YT, Lee JH, Yoo IK, Lee JM, Kim SH, Choi HS, Kim ES, Keum B, Lee HS, Chun HJ, Kim CD (2017) Comparison of a split-dose bowel preparation with 2 liters of polyethylene glycol plus ascorbic acid and 1 liter of polyethylene glycol plus ascorbic acid and bisacodyl before colonoscopy. Gastrointest Endosc 86(2):343-348. https://doi.org/10.1016/j.gie.2016.10.040

7. Kherad O, Restellini S, Martel M, Barkun AN (2015) Polyethylene glycol versus sodium picosulfalte bowel preparation in the setting of a colorectal cancer screening program. Can J Gastroenterol Hepatol 29(7):384-390. https://doi.org/10.1155/2015/350587

8. Banerjee R, Chaudhari H, Shah N, Saravanan A, Tandan M, Reddy DN (2016) Addition of lubiprostone to polyethylene glycol (PEG) enhances the quality \& efficacy of colonoscopy preparation: a randomized, double-blind, placebo controlled trial. BMC Gastroenterol 16(1):133. Published 2016 Oct 13. https:// doi.org/10.1186/s12876-016-0542-0

9. Stengel JZ, Jones DP (2008) Single-dose lubiprostone along with split-dose PEG solution without dietary restrictions for bowel cleansing prior to colonoscopy: a randomized, double-blind, placebo-controlled trial. Am J Gastroenterol 103(9):2224-2230. https://doi.org/10.1111/j.1572-0241.2008.02 053.x

10. Wilson N, Schey R (2015) Lubiprostone in constipation: clinical evidence and place in therapy. Ther Adv Chronic Dis 6(2):40-50. https://doi.org/10.1177/2 040622314567678

11. Bijvelds MJC, Bot AG, Escher JC, de Jonge HR (2009) Activation of intestinal $\mathrm{Cl}$ - secretion by lubiprostone requires the cystic fibrosis transmembrane conductance regulator. Gastroenterology 137(3):976-985 Available from: https://doi.org/10.1053/j.gastro.2009.05.037 
12. McKeage K, Plosker GL, Siddiqui MA (2006) Lubiprostone. Drugs 66(6):873879. https://doi.org/10.2165/00003495-200666060-00015

13. ASGE Standards of Practice Committee, Saltzman JR, Cash BD, Pasha SF, Early DS, Muthusamy VR, Khashab MA, Chathadi KV, Fanelli RD,

Chandrasekhara V, Lightdale JR, Fonkalsrud L, Shergill AK, Hwang JH, Decker GA, Jue TL, Sharaf R, Fisher DA, Evans JA, Foley K, Shaukat A, Eloubeidi MA, Faulx AL, Wang A, Acosta RD (2015) Bowel preparation before colonoscopy. Gastrointest Endosc 81(4):781-794. https://doi.org/10.1016/j.gie.2014.09.048

14. Harewood GC, Sharma VK, de Garmo P (2003) Impact of colonoscopy preparation quality on detection of suspected colonic neoplasia. Gastrointest Endosc 58(1):76-79. https://doi.org/10.1067/mge.2003.294

15. Froehlich F, Wietlisbach V, Gonvers JJ, Burnand B, Vader JP (2005) Impact of colonic cleansing on quality and diagnostic yield of colonoscopy: the European Panel of Appropriateness of Gastrointestinal Endoscopy European multicenter study. Gastrointest Endosc 61(3):378-384. https://doi.org/10.101 6/S0016-5107(04)02776-2

16. Chokshi RV, Hovis CE, Hollander T, Early DS, Wang JS (2012) Prevalence of missed adenomas in patients with inadequate bowel preparation on screening colonoscopy. Gastrointest Endosc 75(6):1197-1203. https://doi. org/10.1016/j.gie.2012.01.005

17. Lebwohl B, Kastrinos F, Glick M, Rosenbaum AJ, Wang T, Neugut Al (2011) The impact of suboptimal bowel preparation on adenoma miss rates and the factors associated with early repeat colonoscopy. Gastrointest Endosc 73(6):1207-1214. https://doi.org/10.1016/.gie.2011.01.051

18. Rostom A, Jolicoeur E (2004) Validation of a new scale for the assessment of bowel preparation quality. Gastrointest Endosc 59(4):482-486. https://doi. org/10.1016/50016-5107(03)02875-X

19. Aoun E, Abdul-Baki H, Azar C, Mourad F, Barada K, Berro Z, Tarchichi M, Sharara Al (2005) A randomized single-blind trial of split-dose PEGelectrolyte solution without dietary restriction compared with whole dose PEG-electrolyte solution with dietary restriction for colonoscopy preparation. Gastrointest Endosc 62(2):213-218. https://doi.org/10.1016/S0016-51 07(05)00371-8

20. Enestvedt BK, Tofani C, Laine LA, Tierney A, Fennerty MB (2012) 4-Liter splitdose polyethylene glycol is superior to other bowel preparations, based on systematic review and meta-analysis. Clin Gastroenterol Hepatol 10(11): 1225-1231. https://doi.org/10.1016/..cgh.2012.08.029

21. Park SS, Sinn DH, Kim YH, Lim YJ, Sun Y, Lee JH, Kim JY, Chang DK, Son HJ, Rhee PL, Rhee JC, Kim JJ (2010) Efficacy and tolerability of split-dose magnesium citrate: low volume (2 liters) polyethylene glycol vs. single-or split-dose polyethylene glycol bowel preparation for morning colonoscopy. Am J Gastroenterol 105(6):1319-1326. https://doi.org/10.1038/ajg.2010.79

22. Ell C, Bitoun A, Goerg K, Halphen M, Gruss H-J (2005) Meta-analysis to assess the influence of two different schedules of intake on the efficacy, acceptability and safety of a new 2 litre PEG $+E$ gut cleansing solution. Gastrointest Endosc 61:AB151

\section{Publisher's Note}

Springer Nature remains neutral with regard to jurisdictional claims in published maps and institutional affiliations.

\section{Submit your manuscript to a SpringerOpen ${ }^{\circ}$ journal and benefit from:}

- Convenient online submission

- Rigorous peer review

- Open access: articles freely available online

- High visibility within the field

- Retaining the copyright to your article

Submit your next manuscript at $\boldsymbol{\nabla}$ springeropen.com 